\title{
Mechanochemical Synthesis of Nano Calcium Silicate Particles at Room Temperature
}

\author{
Shiv Prakash Singh, Basudeb Karmakar*
}

Glass Science and Technology Section, Glass Division, Central Glass and Ceramic Research Institute, Kolkata, India. Email: basudebk@cgcri.res.in

Received March 24 ${ }^{\text {th }}$, 2011; revised April 21 ${ }^{\text {st }}, 2011$; accepted April 28 ${ }^{\text {th }}, 2011$.

\begin{abstract}
Nano-sized calcium silicate powders were synthesized at room temperature by the new mechanochemical method using a high energy planetary ball mill. The formation of calcium silicate from its raw materials (calcium carbonate and dehydrated silica gel) was monitored by the XRD analysis with progression of ball milling. It is observed that the synthetic process comes to an end through the following three sequential stages: comminution of raw materials, recombination of comminuted raw materials to final product, and comminution of final product to smaller sizes. The nanostructure of the synthesized powder was realized by the FESEM photomicrograph, TEM image and XRD analyses. These analytical observations have revealed that the nano-sized polycrystalline calcium silicate particles are formed after about $6 \mathrm{~h}$ of ball milling and they are spheroidal in shape. The average particle size of the as-generated calcium silicate nanocrystalline powders is found to be around $21 \mathrm{~nm}$ which decreases with increasing ball milling but increases with annealing at elevated temperature.
\end{abstract}

Keywords: Mechanochemical Processing, Calcium Silicate Nanoparticle, XRD, FESEM, TEM

\section{Introduction}

Calcium silicate has received significant attention because of their potential applications as host of phosphors and ceramic insulators [1-3]. Nanosized calcium silicate material has been studied over the past years because of their significant properties which are different from their bigger sizes. Conventionally, calcium silicate is prepared by the solid state reaction of $\mathrm{CaO}$ or $\mathrm{CaCO}_{3}$ and quartz $\left(\mathrm{SiO}_{2}\right)$ at $1150^{\circ} \mathrm{C}-1200^{\circ} \mathrm{C}$ for several hours [1-2]. It is also prepared by the chemical methods such as combustion, sol-gel, co-precipitation, etc. routes followed by heat treatment at various temperatures [3-5]. All these methods are limited by some of their inherent disadvantages, for example, requirement of high temperature, long processing time, low yield or hazardous to health and environment.

Recently, synthesis of nanomaterials by mechanochemical route opens up a new page in the nanoscience and nanotechnology. It is a quite simple, energy saving, low-cost, industrially scalable and viable non-conventional technique for the preparation of homogeneous and nano-sized (1 - $100 \mathrm{~nm})$ multicomponent materials [6-9]. It is an environmentally friendly solvent-free and waste- free synthetic route as well unlike chemical methods. The main advantage of the mechanochemical method is that the solid-state reactions are carried out at room temperature instead of high temperature. Practically, it is a high energy milling process that involves repeated mixing, deformation, comminuting, welding and re-welding of the reactant powder particles in a closed vial of a planetary ball mill [10-13]. Here, the solid-state reactions are progressed by the kinetic energy transferred from the milling balls to the milled powders. Its versatility gives the impressions that the mechanochemical method is a promising novel technique for the synthesis of various advanced nanopowder materials. To the best of our knowledge, the synthesis of calcium silicate nanoparticles by the mechanochemical method has not been explored previously.

In this letter, we demonstrate the mechanochemical synthesis of calcium silicate nanoparticles from the calcium carbonate and silica gel at room temperature without applying additional heat treatment. Its synthesis is recognized by the FESEM photomicrograph, TEM image and XRD analyses. 


\section{Experimental Procedure}

The starting raw materials were high purity calcium carbonate, $\mathrm{CaCO}_{3}(99 \%$, Fluka, Switzerland) and dehydrated silica gel, $\mathrm{SiO}_{2}$ (99\%, Fluka, Switzerland). A stoichiometric mixture of these raw materials equivalent to $5 \mathrm{~g}$ calcium silicate was ball milled in a $500 \mathrm{ml}$ zirconia jar with 100 numbers of $10 \mathrm{~mm}$ diameter zirconia milling balls at $300 \mathrm{rpm}$ in a high energy planetary ball mill (PM 100, Retsch). Separate samples were prepared by varying the milling duration such as $1,3,6,10,15,20$ and $26 \mathrm{~h}$. One sample of $26 \mathrm{~h}$ duration was annealed at $750^{\circ} \mathrm{C}$ for $10 \mathrm{~h}$ in air to confirm the completion of synthesis by the mechanochemical method and also to observe the effect of heating on the mechanochemically synthesized calcium silicate at elevated temperature.

The XRD patterns of the staring raw materials mixture and as-milled product samples were recorded at $25^{\circ} \mathrm{C}$ with X'pert Pro MPD diffractometer (PANalytical) operating at $45 \mathrm{kV}$ and $35 \mathrm{~mA}$ using Ni-filtered $\mathrm{CuK} \alpha(\lambda=$ $1.5406 \AA$ ) radiation and the X'celerator with step size $0.05^{\circ}(2 \theta)$ and step time $0.5 \mathrm{sec}$ from $10^{\circ}$ to $80^{\circ}$. FESEM photomicrographs were recorded with a Gemini Zeiss Supra $^{\mathrm{TM}}$ 35VP Model (Carl Zeiss) instrument using an accelerating voltage of $4.9 \mathrm{kV}$. TEM images were taken using a FEI instrument (TECHNAI G2) operating at the accelerating voltage of $300 \mathrm{kV}$.

\section{Results and Discussion}

Calcium silicate $\left(\mathrm{CaSiO}_{3}\right)$ is synthesized from the raw materials, calcium carbonate $\left(\mathrm{CaCO}_{3}\right)$ and dehydrated silica $\left(\mathrm{SiO}_{2}\right)$ gel, by the mechanochemical method using a high energy planetary ball mill. Its solid state synthesis reaction which occurred in this method at room temperature could be represented by

$$
\mathrm{CaCO}_{3}+\mathrm{SiO}_{2}=\mathrm{CaSiO}_{3}+\mathrm{CO}_{2} \uparrow
$$

The synthesis of nano calcium silicate particles has found to be progressed in this method through the following three sequential stages. It is also more clearly depicted in Figure 1.

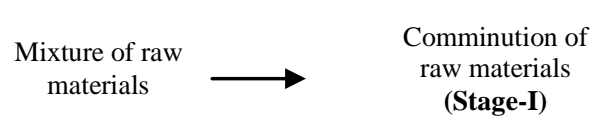

The effects of milling time on the generation and subsequent comminution of calcium silicate are monitored by the XRD patterns by comparing with its standard XRD pattern (JCPDS File Card No. 27-0088). These are shown in Figure 2. The particle sizes were calculated using the following Scherrer's formula [14]:

$$
\mathrm{D}=0.9 \lambda / \mathrm{B} \cos 2 \theta \text { (peak) }
$$

where $D$ is diameter of the calcium silicate particle, $\lambda$ is wavelength of $\mathrm{CuK} \alpha$ radiation $(\lambda=1.5406 \AA), B$ is full width at half maximum (FWHM) of the intensity peak and $2 \theta$ is diffraction angle at maxima of high intensity peak in the patterns.

Figure 2 shows that during early stage of milling (up to $3 \mathrm{~h}$ ) there is no evidence of calcium silicate formation but only the comminution of starting raw materials, e.g., calcium carbonate, down to $11 \mathrm{~nm}$. Then after the particle size instantly increases $(21 \mathrm{~nm})$ up to $6 \mathrm{~h}$ of milling with generation of calcium silicate. Between 3 and $6 \mathrm{~h}$ of milling the qualitative change of XRD patterns due to calcium silicate formation is clearly visible. This observation shows that during this period of milling the particles are severely deformed, amorphized and re-combined due to high energy impacts of the milling balls. At $6 \mathrm{~h}$ of milling, it clearly shows the calcium silicate peaks which confirm the formation of calcium silicate crystalline
Recombination of comminuted raw materials to final product (Stage-II)

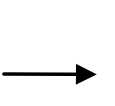

Comminution of final product to smaller sizes

(Stage-III) phase by the mechanochemical method. Subsequently, the particle size of the as-generated calcium silicate decreases down to $13 \mathrm{~nm}$ and the peak intensities increases with increase in milling time, that is, $6 \mathrm{~h}$ onward. Thus, the synthesis of more calcium silicate gradually increases along with reduction of its sizes with increasing milling time.

Further qualitative changes are observed after $10 \mathrm{~h}$ of milling in the XRD patterns. It shows more prominent development of $\langle 320\rangle$, $<-432>$ and $<-921>$ hkl planes of calcium silicate (JCPDS File Card No. 27-0088). The information obtained from XRD patterns analyses agree well with the field emission scanning electron microscopy (FESEM) photomicrograph as shown in Figure 3(a). FESEM observations revealed the material morphology with milling time by mechanochemical treatment. The as-prepared sample after $10 \mathrm{~h}$ milling indicates that the synthesized calcium silicate particles are joined with each other due to recombination reactions thereby increases the sizes as observed in the XRD. This is already shown in the Figure 1. The transmission electron microscopy (TEM) image of the neck of two particles and its SAED pattern are shown in Figure 4(a). The formation of calcium silicate was started around $6 \mathrm{~h}$ of milling. Further milling, the calcium silicate gradually developed broad XRD peaks without any characteristic changes of the 


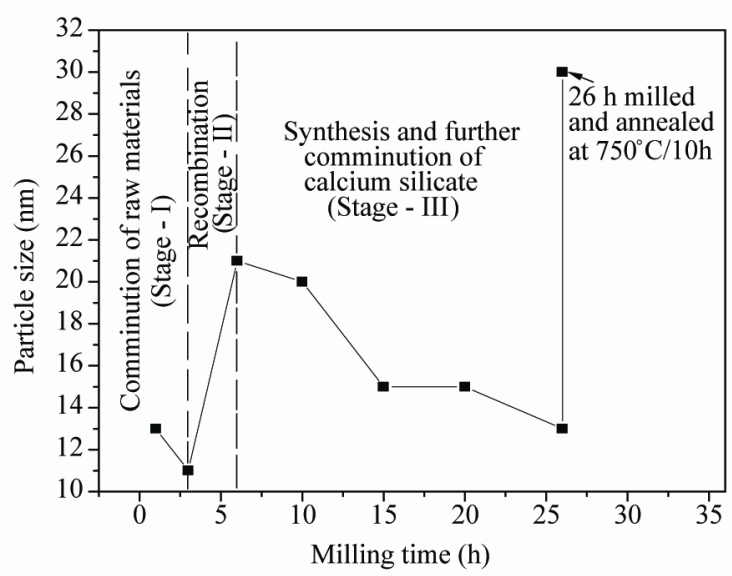

Figure 1. The particle size as a function of milling time.

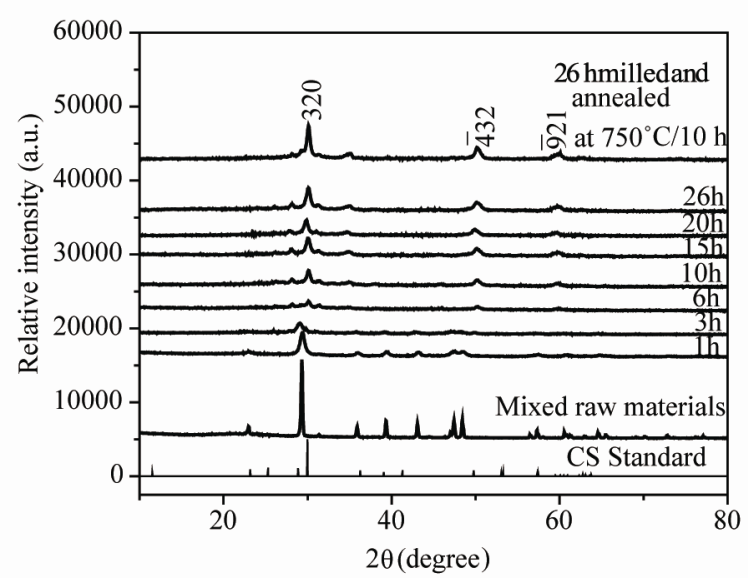

Figure 2. X-ray diffraction patterns of samples milled for different duration and the $26 \mathrm{~h}$ milled sample annealed at $750^{\circ} \mathrm{C}$ (Top). The standard pattern (JCPDS File Card No. 27-0088) of calcium silicate (CS) is also shown for comparison (Bottom).

patterns which point towards the gradual reduction of its particle size with increasing milling time, as realized by evaluating using the Equation (2).

The main changes occur after $26 \mathrm{~h}$ of milling is that its particle sizes reduced to about $13 \mathrm{~nm}$ as calculated from XRD. The morphological changes of $26 \mathrm{~h}$ milled calcium silicate particles are also clearly visible in the FESEM photomicrograph as shown in Figure 3(b). The synthesized calcium silicates separated from each other and get their defined morphological shapes which are spheroidal in nature. The transmission electron microscope (TEM) image and the SAED pattern, as shown in Figure 4(b), illustrate the polycrystallinity of the mechanochemically synthesized calcium silicate. The TEM image also shows the rough and irregular characteristics of the surfaces of calcium silicate particles. It is very difficult to conclude the same with only the FESEM photomicrograph as shown in the Figure 3(b). However, the TEM image gives the unambiguous view.

We have annealed the synthesized calcium silicate after $26 \mathrm{~h}$ of milling at $750^{\circ} \mathrm{C}$ for $10 \mathrm{~h}$ in an electrical furnace to confirm the completion of synthesis of calcium silicate by the mechanochemical method at $6 \mathrm{~h}$ or onward. Its XRD pattern is shown at the top of the Figure 2. It is seen that the width of peaks of the XRD pattern of the annealed powder reduces with increase in their intensities but without any additional peak. Thus, it indicates only the growing of the calcium silicate particle size due to fusion or sintering of smaller particles on annealing at $750^{\circ} \mathrm{C}$. The heat treated powders do not exhibit any new XRD peak which clearly depicts that the solid state reaction has completed in the mechanochemical process and no further new compound is formed even though after application of high temperature.

\section{Conclusions}

Synthesis of calcium silicate nanoparticles at room temperature by the new mechanochemical method has been demonstrated. The formation of calcium silicate has been recognized by the FESEM photomicrograph, TEM image and XRD analyses. It is observed that the syn thetic process comes to an end through the following

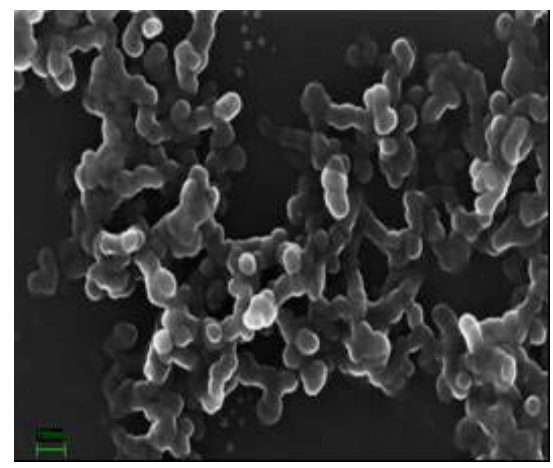

(a)

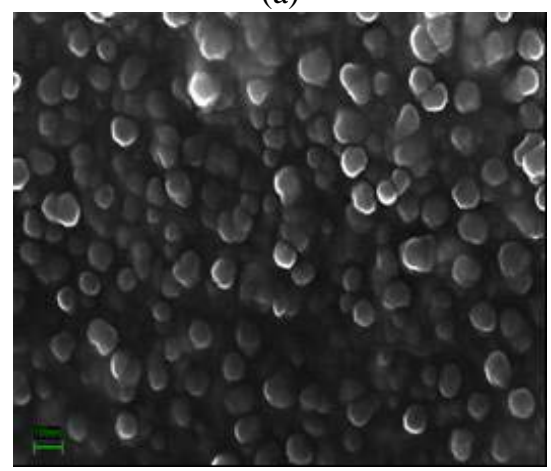

(b)

Figure 3. FESEM photomicrographs of samples obtained after (a) 10 and (b) $26 \mathrm{~h}$ of milling. 


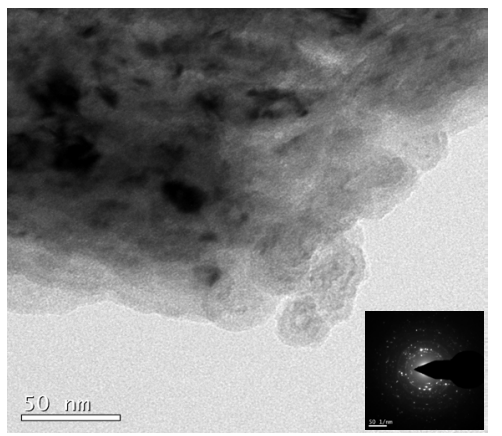

(a)

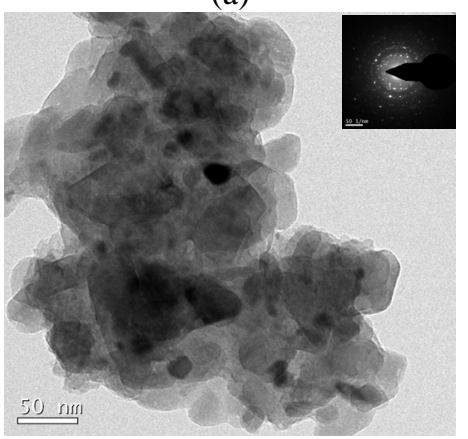

(b)

Figure 4. TEM images and SAEDs (insets) of samples obtained after (a) 10 and (b) $26 \mathrm{~h}$ of milling.

three sequential stages: comminution of raw materials, recombination of comminuted raw materials to final product, and comminution of final product to smaller sizes. The nano-sized polycrystalline calcium silicate particles are found to generate after about $6 \mathrm{~h}$ of ball milling and they are spheroidal in shape. The average particle size of the as-generated particles is found to be around $21 \mathrm{~nm}$ which decreases down to $13 \mathrm{~nm}$ with increasing ball milling but increases up to $30 \mathrm{~nm}$ after annealing at $750^{\circ} \mathrm{C}$. The annealed sample does not show any new XRD peaks, therefore, it authenticates the completion of the solid state synthesis reactions of calcium silicate at room temperature by the mechanochemical method using high energy planetary ball milling. We believe that this work would open a new vista in the area of nanoparticle research.

\section{Acknowledgements}

The authors gratefully acknowledge the financial support of NMITLI, CSIR, New Delhi. They gratefully thank Director of the institute for his kind permission to publish this paper. The technical supports obtained from the infrastructural facilities (XRD and Electron Microscope Divisions) of this institute are also thankfully acknowledged.

\section{REFERENCES}

[1] W. M. Yen and M. J. Weber, "Inorganic Phosphors:
Compositions, Preparation and Optical Properties,” CRC Press, Boca Raton, 2004. doi: 10.1201/9780203506325

[2] S. Kamiya and H. Mizuno, "Phosphors for Lamps,” In: S. Shionoya and W. N. Yen, Eds., Phosphor Handbook, CRC Press, Boca Raton, 1999, pp. 389-444.

[3] T. I. Khristov, N. V. Popovich and S. S. Galaktionov, "Calcium Silicate Phosphors Obtained by the Sol-Gel Method,” Glass and Ceramics, Vol. 51, No. 9-10, 1994, pp. 7-12. doi:10.1007/BF00679827

[4] S. J. Dhoble, N. S. Dhoble and R. B. Pode, "Preparation and Characterization of $\mathrm{Eu}^{3+}$ Activated $\mathrm{CaSiO}_{3},(\mathrm{CaA}) \mathrm{SiO}_{3}$ [A = Ba or Sr] Phosphors,” Bulletin of Materials Science, Vol. 26, No. 4, 2003, pp. 377-382. doi:10.1007/BF02711179

[5] Y. Nishisu, M. Kobayashi, H. Ohya and T. Akiya, "Preparation of Eu-Doped Alkaline-Earth Silicate Phosphor Particles by Using Liquid-Phase Synthesis Method," Journal of Alloys and Compounds, Vol. 408-412, 2006, pp. 898-902. doi:10.1016/j.jallcom.2005.01.101

[6] C. L. Chew, A. Srinivas, T. Sritharan and F. Y. C. Boey, "Mechanochemical Activation of Strontium Bismuth Tantalate Synthesis," Scripta Materialia, Vol. 53, 2005, pp. 1197-1199. doi:10.1016/j.scriptamat.2005.07.009

[7] Q. Zhang and F. Saito, "Mechanochemical Synthesis of Lanthanum Aluminate by Grinding Lanthanum Oxide with Transition Alumina," Journal of the American Ceramic Society, Vol. 83, No. 2, 2000, pp. 439-441. doi:10.1111/j.1151-2916.2000.tb01215.x

[8] D. Domanski, G. Urretavizcaya, F. J. Castro and F. C. Gennari, "Mechanochemical Synthesis of Magnesium Aluminate Spinel Powder at Room Temperature,” Journal of the American Ceramic Society, Vol. 87, No. 11, 2004, pp. 2020-2024. doi:10.1111/j.1151-2916.2004.tb06354.X

[9] I. Bergmann, V. Šepelák and K. D. Becker, "Preparation of Nanoscale $\mathrm{MgFe}_{2} \mathrm{O}_{4}$ via Non-Conventional Mechanochemical Route,” Solid State Ionics, Vol. 177, No. 19-25, 2006, pp. 1865-1868.

[10] T. Rojac, M. Kosec, B. Malič and J. Holc, "The Application of a Milling Map in the Mechanochemical Synthesis of Ceramic Oxides," Journal of the European Ceramic Society, Vol. 26, No. 16, 2006, pp. 3711-3716. doi:10.1016/j.jeurceramsoc.2005.11.013

[11] J. Lee, Q. Zhang and F. Saito, "Mechanochemical Synthesis of Lanthanum Oxyfluoride from Lanthanum Oxide and Lanthanum Fluoride,” Journal of the American Ceramic Society, Vol. 84, No. 4, 2001, pp. 863-865. doi:10.1111/j.1151-2916.2001.tb00753.x

[12] T. Sritharan, F. Y. C. Boey, A. Srinivas, "Synthesis of Complex Ceramics by Mechanochemical Activation," Journal of Materials Processing Technology, Vol. 192193, 2007, pp. 255-258.

[13] M. Shoji and K. Sakurai, "A Versatile Scheme for Preparing Single-Phase Yttrium Oxysulfate Phosphor," Journal of Alloys and Compounds, Vol. 426, No. 1-2, 2006, pp. 244-246. doi:10.1016/j.jallcom.2005.12.110

[14] B. D. Cullity, "Elements of X-Ray Diffraction,” 2nd Edition, Addison-Wesley, Massachusetts, 1978. 